\title{
Falls in persons with Parkinson's disease: Do non-motor symptoms matter as much as motor symptoms?
}

\author{
Caídas en personas con enfermedad de Parkinson: ¿Los síntomas no motores importan \\ tanto como los síntomas motores?
}

\author{
Alonso ALVARADO-BOLAÑOS ${ }^{1}$, Amin CERVANTES-ARRIAGA ${ }^{1}$, Kenia ARREDONDO-BLANCO², Karla \\ SALINAS-BARBOZA2, Sara ISAIS-MILLÁN², Mayela RODRIGUEZ-VIOLANTE ${ }^{1,2}$
}

\begin{abstract}
Falls are common among persons with Parkinson's disease (PD). On the other hand, predicting falls is complex as there are both generic and PD-specific contributors. In particular, the role of non-motor symptoms has been less studied. Objective: The objective of this study was to identify the role of non-motor predictors of falling in persons with PD (PwP). Methods: A cross-sectional study was carried out in PwP recruited from a movement disorders clinic. Clinical and demographical data were collected. All PwP were assessed using the Movement Disorders Society Unified Parkinson's Disease Rating Scale (MDS-UPDRS) and the Non-Motor Symptoms Scale (NMSS). Variables were assessed at the bivariate level. Significant variables were put into a logistic regression model. Results: A total of 179 PwP were included. Overall, $16.8 \%$ of PwP had fallen in the past 12 months, with $53.3 \%$ of them being recurrent fallers. The mean number of monthly falls was $2.5 \pm$ 3.3. Factors associated with falling in the bivariate analysis included the disease duration, Hoehn and Yahr stage, MDS-UPDRS part I and II, postural instability/gait disturbance (PIGD) subtype, NMSS urinary domain, NMSS miscellaneous domain, and non-motor severity burden (all p-values <0.05). After multivariate analysis, only the disease duration ( $p=0.03$ ) and PIGD ( $p=0.03)$ remained as independent risk factors. Conclusion: Disease duration and the PIGD subtype were identified as relevant risk factors for falls in PwP. Non-motor symptoms appear to have a less important role as risk factors for falls.
\end{abstract}

Key words: Parkinson disease; accidental falls; risk factors; motor disorders; neurologic manifestations.

\section{RESUMEN}

Las caídas son frecuentes entre las personas con Parkinson (EP). La predicción de caídas es compleja ya que existen contribuyentes genéricos y específicos. El papel de los síntomas no motores ha sido menos estudiado. Objetivo: Identificar el papel de los factores no motores en caídas en personas con EP (PcP). Métodos: Estudio transversal en PcP reclutadas en una clínica de trastornos del movimiento. Se incluyeron datos clínicos y demográficos. Todos los PcP se evaluaron con la Escala Unificada de Enfermedad de Parkinson modificada por la Sociedad Internacional de Trastornos del Movimiento (MDS-UPDRS) y la Escala de Síntomas No Motores (NMSS). Se incluyeron variables significativas en un modelo de regresión logística. Resultados: Se incluyeron un total de 179 PcP. El 16.8\% había presentado una caída en los últimos doce meses y el 53.3\% de forma recurrente. El número medio de caídas mensuales fue de $2.5 \pm 3.3$. Los factores asociados con la caída en el análisis bivariado fueron la duración de la enfermedad, Hoehn e Yahr, MDS-UPDRS parte I y II, subtipo de alteración de la marcha/inestabilidad postural (PIGD), dominio urinario del NMSS, dominio misceláneo del NMSS y carga de severidad no motora (todos los valores de $p<0.05)$. Después del análisis multivariado, solo la duración de la enfermedad ( $p=0.03$ y PIGD ( $p=0.03)$ permanecieron como un factor de riesgo independiente. Conclusión: La duración de la enfermedad y PIGD se identificaron como factores de riesgo para caídas. Los síntomas no motores parecen tener un papel menos relevante en las caídas.

Palabras clave: Enfermedad de Parkinson; accidentes por caídas; factores de riesgo; trastornos motores; manifestaciones neurológicas.

Falls occur frequently among persons with Parkinson's disease (PD). The reported frequency varies across studies but is estimated to be around $60 \%$. In addition, recurrent fallers represent up to $39 \%^{1}$. Falls are also correlated with a worse quality of life, reduced life expectancy, and loss of independence $^{2}$. Predicting risk of falling is complex due to its

\footnotetext{
${ }^{1}$ Instituto Nacional de Neurología y Neurocirugía, Laboratorio Clínico de Enfermedades Neurodegenerativas, Mexico City, Mexico; Instituto Nacional de Neurología y Neurocirugía, Clínica de Trastornos del Movimiento, Mexico City, Mexico.

Correspondence: Mayela Rodríguez-Violante; Movement Disorders Clinic, National Institute of Neurology and Neurosurgery; Insurgentes Sur \#3877 Col. La Fama 14269 Mexico City, Mexico; E-mail:mrodriguez@innn.edu.mx
}

Alonso Alvarado-Bolaños iD https://orcid.org/0000-0001-8088-4907; Amin Cervantes-Arriaga iD https://orcid.org/0000-0002-3935-9278; Mayela Rodríguez-Violante (iD) https://orcid.org/0000-0002-6041-9941

Conflict of interest: There is no conflict of interest to declare.

Received 05 June 2019; Received in final form 15 July 2019; Accepted 28 July 2019. 
multifactorial nature. Contributing factors have been divided into generic and PD-specific, with very varied results ${ }^{3}$. The generic risk factors mainly include age, gender, visual impairment, cardiovascular disease and other comorbidities. The PD-specific factors include disease severity and are focused on motor symptoms such as slow mobility, freezing of gait, axial rigidity and posture instability.

On the other hand, fewer studies specifically addressing the role of non-motor symptoms (NMS) have been carried out. Most of these risk factors are known predictors of falls in the elderly, such as depression and cognitive impairment. However, the role of the full spectrum of NMS present in persons with $\mathrm{PD}(\mathrm{PwP})$ as risk factors for fall has not been addressed. As a consequence, the contribution of each independent motor and non-motor risk factor, as well as their interactions, remain only partially understood.

The objective of this study was to assess the role of NMS in the risk of falling in PwP along with motor and clinical factors.

\section{METHODS}

A cross-sectional study was carried out, including consecutive PwP attending the movement disorders clinic at the National Institute of Neurology and Neurosurgery in Mexico City. The PwP were eligible according to accepted criteria $^{4}$. Clinical and demographic data were collected, including disease duration and fall occurrence in the past 12 months. The levodopa equivalent daily dose was calculated, as published elsewhere ${ }^{5}$. All examining neurologists had experience in the assessment of movement disorders. The PwP were classified as fallers (at least one fall in the past 12 months) or non-fallers. Recurrent fallers were defined as having two or more falls in the last year. The following clinical tools were applied: the Hoehn and Yahr scale $(\mathrm{HY})^{6}$, Movement Disorders Society Unified Parkinson's Disease Rating Scale (MDS-UPDRS) ${ }^{7}$, and Non-Motor Symptoms Scale (NMSS) $)^{8,9}$.

Also, a tremor score and a postural instability/gait disturbance (PIGD) score were used to determine the motor subtype, as published by Stebbins et al. ${ }^{9}$. All sections of the MDS-UPDRS were applied to evaluate non-motor experiences of daily living (part I), motor experiences of daily living (part II), motor examination (part III) and motor complications (part IV). The NMSS was used to assess both the presence and severity of non-motor symptoms. This scale evaluates 30 items grouped into nine relevant domains: cardiovascular (two items); sleep/fatigue (four items); mood/ cognition (six items); perceptual problems/hallucinations (three items); attention/memory (three items); gastrointestinal tract (three items); urinary (three items); sexual function (two items); and miscellaneous items evaluating pain, olfactory alterations, weight loss, and excessive sweating. The score for each item is based on a multiple of the severity score (from 0 to 3 ) and the frequency score (from 1 to 4). Burden levels on the NMSS were defined for both severity (defined by the NMSS total score) and load (defined by the number of NMS declared by the PwP). Regarding NMS severity burden levels, the PwP were classified as: no NMS (score of 0), mild (score 1-20), moderate (score 21-40), severe (score 41-70) and very severe (score 71 or more) ${ }^{10}$. The PwP were also classified according to the NMS load burden as no NMS (0 symptoms), mild (1-5 NMS), moderate (6-9 NMS), severe (10-13 NMS) and very severe (14 or more NMS $)^{11}$.

The study was approved by the Institutional Review Board. All participants provided full written consent for participation in this study.

\section{Statistical analysis}

Normal distribution of all variables was evaluated according to the Shapiro-Wilk test. Comparisons among groups of fallers and non-fallers were conducted. Quantitative data was analyzed using the independent Student's t-test or a oneway analysis of variance (or nonparametric equivalent), as needed. Qualitative variables were compared using the $\mathrm{X}^{2}$ test or the Fisher's Exact test, as appropriate. Variables with statistically significant differences in the bivariate analyses were put into a logistic regression model with the presence of falls in the past 12 months as the dependent variable. Variables were assessed for multicollinearity using variation inflation factors. The Hosmer-Lemeshow test was used for goodness of fit. Variance explained by the model was assessed using the Nagelkerke R-squared. A p-value of < 0.05 was considered significant. Statistical analyses were performed using the SPSS, version 17 (SPSS, Inc., Chicago, IL).

\section{RESULTS}

A total of 179 PwP were included in the study. The mean age was $64.6 \pm 12.2$ years and the mean disease duration was $10.4 \pm 7.7$ years. Distribution for disease severity was $65.4 \%$ for HY 1-2, 30.2\% for HY 3 and 4.5\% for HY 4 -5. The mean MDS-UPDRS part III was $26.8 \pm 13.4$. Regarding the motor subtype, 59.8\% were classified as having PIGD, 25.7\% with tremor dominant subtype, and $14.5 \%$ with indeterminate subtype. The mean levodopa equivalent daily dose was 807.1 $\pm 515.1 \mathrm{mg}$. Overall, $16.8 \%$ of PwP had experienced at least one fall in the past 12 months. The mean number of falls per month was $2.5 \pm 3.3$, with $53.3 \%$ being recurrent fallers.

A statistically significantly difference between fallers and non-fallers was found with the following variables: disease duration, disease severity (HY mild and moderate stages), MDS-UPDRS parts I, II and total scores, motor subtype (PIGD for fallers and tremor dominant for non-fallers). A full comparison of clinical and demographic variables is shown in Table 1. 
Regarding severity of NMS, a statistical difference was found in the NMSS total score with fallers scoring higher. When analyzing by individual domain, fallers had a higher score in the NMSS urinary domain as well as in the NMSS miscellaneous domain. As shown in Table 2, no differences were found in the remaining domains.

Table 1. Comparison of clinical and demographic data between fallers and non-fallers.

\begin{tabular}{|c|c|c|c|}
\hline Clinical variables $^{a}$ & Fallers $(n=30)$ & Non-fallers $(n=149)$ & p-value \\
\hline Age (years) & $66.7 \pm 12.1$ & $64.2 \pm 12.3$ & 0.29 \\
\hline Male, n (\%) & $19(63.3)$ & $91(61.1)$ & 0.84 \\
\hline Disease duration (years) & $12.8 \pm 8.4$ & $7.4 \pm 5.6$ & $<0.001$ \\
\hline HY stage & $2.7 \pm 0.9$ & $2.3 \pm 0.7$ & 0.01 \\
\hline HY 1-2, n (\%) & $13(43.3)$ & $104(69.8)$ & 0.01 \\
\hline HY 3, n (\%) & $14(46.7)$ & $40(26.8)$ & 0.03 \\
\hline HY 4-5, n (\%) & $3(10)$ & $5(3.4)$ & 0.10 \\
\hline MDS-UPDRS I & $13.3 \pm 7.1$ & $9.7 \pm 5.6$ & $<0.001$ \\
\hline MDS-UPDRS II & $18.4 \pm 9.6$ & $13.2 \pm 10$ & 0.01 \\
\hline MDS-UPDRS III & $31.0 \pm 13.7$ & $25.9 \pm 13.2$ & 0.06 \\
\hline MDS-UPDRS IV & $0.9 \pm 2.5$ & $1.23 \pm 2.53$ & 0.50 \\
\hline MDS-UPDRS Total & $63.6 \pm 22.7$ & $50.1 \pm 23$ & $<0.05$ \\
\hline Motor subtype TD, n (\%) & $1(3.3)$ & $45(30.2)$ & 0.01 \\
\hline Motor subtype indeterminate, n (\%) & $1(3.3)$ & $25(16.8)$ & 0.06 \\
\hline Motor subtype PIGD n (\%) & $28(93.3)$ & $79(53)$ & $<0.001$ \\
\hline Levodopa, n (\%) & $27(90)$ & $120(80.5)$ & 0.29 \\
\hline Levodopa equivalent daily dose, mg & $954.90 \pm 652.50$ & $777.33 \pm 479.99$ & 0.08 \\
\hline
\end{tabular}

HY: Hoehn and Yahr; MDS-UPDRS: Movement Disorders Society Unified Parkinson's Disease Rating Scale; TD: tremor dominant; PIGD: postural instability and gait disorder.

Table 2. Comparison of non-motor symptoms between groups ${ }^{a}$.

\begin{tabular}{|c|c|c|c|}
\hline Variables & Fallers $(n=30)$ & Non-fallers $(n=149)$ & $p$-value \\
\hline NMSS Cardiovascular & $1.9 \pm 4.5$ & $0.9 \pm 2.4$ & 0.23 \\
\hline NMSS Sleep/fatigue & $11 \pm 13.5$ & $6.1 \pm 10.6$ & 0.07 \\
\hline NMSS Mood/cognition & $12.0 \pm 19.0$ & $6.7 \pm 13.4$ & 0.16 \\
\hline NMSS Perceptual/hallucinations & $3.1 \pm 9.0$ & $0.8 \pm 2.9$ & 0.18 \\
\hline NMSS Attention/memory & $6.2 \pm 11.4$ & $3.0 \pm 6.7$ & 0.15 \\
\hline NMSS Gastrointestinal & $5.3 \pm 5.5$ & $4.0 \pm 5.9$ & 0.25 \\
\hline NMSS Urinary & $10.8 \pm 12.6$ & $5.7 \pm 8.9$ & 0.04 \\
\hline NMSS Sexual function & $0.8 \pm 4.4$ & $1.8 \pm 11.2$ & 0.65 \\
\hline NMSS Miscellaneous & $5.0 \pm 5.4$ & $2.4 \pm 5.2$ & 0.02 \\
\hline NMSS Total Score & $56.1 \pm 47.0$ & $31.5 \pm 33.1$ & 0.01 \\
\hline \multicolumn{4}{|l|}{ NMS Load burden } \\
\hline No NMS & 0 & 0 & -- \\
\hline Mild (1-5) & $2(6.7 \%)$ & $19(12.8 \%)$ & 0.14 \\
\hline Moderate (6-9) & $3(10.0 \%)$ & $33(22.1 \%)$ & 0.13 \\
\hline Severe (10-13) & $10(33.3 \%)$ & $40(26.9 \%)$ & 0.47 \\
\hline Very severe (>13) & $15(50.0 \%)$ & $57(38.2 \%)$ & 0.23 \\
\hline \multicolumn{4}{|l|}{ NMS Severity burden } \\
\hline No NMS & 0 & 0 & -- \\
\hline Mild (1-20) & $8(26.7 \%)$ & $73(49 \%)$ & 0.02 \\
\hline Moderate (21-40) & $9(30.0 \%)$ & $39(26.2 \%)$ & 0.66 \\
\hline Severe (41-70) & $1(3.3 \%)$ & $13(8.7 \%)$ & 0.32 \\
\hline Very Severe (> 70) & $12(40.0 \%)$ & $24(16.1 \%)$ & 0.01 \\
\hline
\end{tabular}

NMSS: Non-Motor Symptom Scale; NMS: non-motor symptoms. ${ }^{a}$ Data are mean \pm SD; or absolute numbers and percentages 
After categorizing by NMS severity burden, fallers had a "very severe" burden while non-fallers had a "mild" burden (Table 2). On the other hand, no differences were found when comparing the NMS load burden between groups (17.4 \pm 8.7 among fallers, $14.8 \pm 9.3$ among non-fallers; $\mathrm{p}=0.16$ ).

A logistic regression model was designed using variables with differences in the bivariate analyses. The MDS-UPDRS total score was not included in the model to avoid multicollinearity (variation inflation factors $=5.1$ ) with MDS-UPDRS parts I and II scores. In addition, a new MDS-UPDRS part I score, subtracting items 1.9 (pain) and item 1.10 (urinary problems), was calculated to avoid collinearity with the NMSS domains evaluating these symptoms. This new MDSUPDRS part I partial score maintained a statistically significant difference between groups $(\mathrm{p}=0.01)$.

Similarly, the NMSS total was also excluded due to multicollinearity (variation inflation factors $=5.03$ ) with the genitourinary and miscellaneous domains. No significant multicollinearity was found between the remaining variables. The variables included in the model were disease duration, HY stage, motor subtype, MDS-UPDRS part I score, MDSUPDRS part II score, NMSS genitourinary score, NMSS miscellaneous score, and NMS severity burden. After the regression analysis, only the disease duration and PIGD subtype remained significant. Data derived from multivariate analysis are shown in Table 3. The Hosmer-Lemeshow test showed goodness of fit $\left(\chi^{2}=7.12, \mathrm{df}=8, \mathrm{p}=0.524\right)$ and the Nagelkerke $\mathrm{R}$-squared was 0.32 . This multivariate model correctly classified the outcome for $84.9 \%$ of the cases.

\section{DISCUSSION}

The proportion of fallers among our sample was very low (16.8\%). Prospective studies have reported falling frequency at three months follow-up to range between $36 \%$ and $59 \%^{12}$, whereas retrospective studies have reported $31 \%$ and $32.9 \%$ in the previous month and year, respectively ${ }^{13,14}$. Interestingly, some studies have assessed falling frequency in both prospective and retrospective ways with mixed results. In one study the incidence of falls reported by anamnesis (retrospective analysis) did not differ from the prospective assessment after one year ${ }^{15}$. Another study found that $79.7 \%$ of participants fell over 54 months compared with $26.2 \%$ of participants who reported retrospective falls at baseline ${ }^{16}$. The low proportion of fallers in our sample could partially be explained by underrepresentation of advanced forms of the disease, with only 4.5\% being at HY 4-5 stages.

The difficulty designing accurate fall prediction models highlights the complexity of fall risk. Generic age-related risk factors are well known and include age, female sex, polypharmacy, autonomic dysfunction, arthrosis, visual impairment, and depression, among others ${ }^{3}$. Many prediction models have been proposed with varying results. A meta-analysis of six prospective studies $(n=473)$ found that the strongest predictor of falling was prior falls in the preceding year. Although relevant, recurrent falling is of limited use for prevention models and was not further evaluated in our study. This large meta-analysis also failed to identify disease severity as a significant predictor of falls ${ }^{12}$.

In our study, the severity of motor symptoms failed to predict falling. This finding is consistent with other studies that have failed to show motor variables as independent predictors of falls ${ }^{13,17}$. The only independent predictor statistically significant at the multivariate level was the disease duration and the PIGD subtype. The PIGD as a risk factor has already been reported ${ }^{18}$ and is consistent with other studies that have identified slow mobility ${ }^{19}$, freezing of gait, posture, postural instability ${ }^{20}$, and axial rigidity ${ }^{21}$ as significant predictors. Conversely, the PIGD subtype has been associated with greater severity of nondopaminergic (mainly cholinergic) symptoms $^{22}$ and greater cognitive impairment ${ }^{23}$, which may account for an increased risk of falling. The frequency of the PIGD subtype in our study was almost $60 \%$, which is in line with the $64 \%$ reported by Stebbins et al. ${ }^{9}$. Nevertheless, it is relevant to consider that it has been proven that the motor

Table 3. Multivariate logistic regression model for predicting falls in people with Parkinson's disease.

\begin{tabular}{|c|c|c|c|c|}
\hline Variable & B & $\operatorname{Exp}(B)$ & $95 \% \mathrm{Cl}$ & $\mathrm{p}$-value \\
\hline Disease duration (years) & 0.06 & 1.06 & $1.01-1.11$ & 0.03 \\
\hline MDS-UPDRS I partial score * & 0.09 & 1.09 & $0.98-1.23$ & 0.12 \\
\hline MDS-UPDRS II & -0.03 & 0.97 & $0.93-1.03$ & 0.32 \\
\hline HY stage & 0.48 & 1.62 & $0.90-2.9$ & 0.11 \\
\hline PIGD Subtype & 2.33 & 10.25 & $1.25-83$ & 0.03 \\
\hline TD subtype & 0.18 & 1.19 & $0.06-24.6$ & 0.91 \\
\hline NMSS urinary & 0.02 & 1.02 & $0.97-1.07$ & 0.50 \\
\hline NMSS miscellaneous & 0.05 & 1.05 & $0.98-1.14$ & 0.19 \\
\hline Mild NMS severity burden & 0.14 & 1.15 & $0.21-6.44$ & 0.88 \\
\hline Very severe NMS severity burden & 0.14 & 0.87 & $0.16-1.49$ & 0.88 \\
\hline
\end{tabular}

MDS-UPDRS: Movement Disorders Society Unified Parkinson's Disease Rating Scale; HY: Hoehn and Yahr stage; PIGD: postural instability and gait disorder; TD: tremor dominant; NMSS: Non-Motor Symptoms Scale; NMS: non-motor symptoms; * MDS-UPDRS part I score minus items 1.9 and 1.10. 
subtype is not stable and tremor dominant/PIGD subtypes can shift category over time ${ }^{24}$. Moreover, Alvarado-Franco et al. reported a shift from tremor dominant to PIGD subtype in Mexican PwP, increasing from $21 \%$ to $42 \%$ over a sixyear follow-up ${ }^{25}$. After multivariate analysis, both the disease duration and PIGD subtype remained as statistically significant predictors but this finding needs further confirmation through a prospective design. In addition, the disease duration in our sample was around eight years and should be considered when interpreting the results.

Motor fluctuations are among the least-consistent predictors. Some authors have suggested an association between dyskinesia and falls ${ }^{17}$, whereas others failed to prove this. The same was true for wearing off, with some suggesting association $^{26}$ and others with inconclusive results ${ }^{17}$. In our sample, no difference was found in the MDS-UPDRS part IV, which assesses both wearing off and dyskinesia.

On the other hand, the association of NMS and falling risk has scarcely been explored. Some studies have associated falling risk with cognitive impairment ${ }^{19,27}$, rapid eye movement sleep behavioral disorders ${ }^{13,28}$, autonomic dysfunction ${ }^{29}$, depression $^{30}$, cardiovascular comorbidity ${ }^{31}$ and urinary incontinence ${ }^{14}$. In our study, in the NMSS genitourinary domain, miscellaneous and total scores were higher among fallers, although none of these variables were shown to be independent predictors within the regression model. One possible explanation for the association between urinary symptoms and falls is through dysautonomia, which may lead to falls. However, in our study, the NMSS cardiovascular domain was not associated with falling. Another possible explanation that needs further study is nocturia, which is often the prevailing factor leading to nighttime falls ${ }^{32}$. The miscellaneous domain evaluates several NMS, including pain, change in taste or smell, change in weight and excessive sweating. Of these items, excessive sweating may be associated with dysautonomia. Weight change also has some theoretical foundation, since a higher body mass index has been linked to falling risk $^{33}$. Unfortunately, the heterogeneity of this domain does not allow strong conclusions. A major limitation of our study was the fact that the patients were not evaluated according to specific recommended tools ${ }^{34,35,36}$ for all NMS, particularly in the case of neuropsychiatric symptoms; therefore screening may not have been ideal.

To the best of our knowledge, this is the first study to explore the NMSS severity and load burdens as potential predictors of falls. We theorized that the number and severity of accumulating NMS could significantly contribute to falling risk. Interestingly, the NMSS severity burden was higher among fallers but did not prove to be an independent predictor after multivariate analysis.

Our study has other limitations. A retrospective assessment of previous history of falls may not be reliable for identifying fall predictors and is subject to recall bias. Nonetheless, similar estimates of fall incidences have been reported using both retrospective and prospective methodologies ${ }^{15}$. As mentioned before, a referral bias was present with the under-representation of PwP in the more severe stages of the disease; therefore, our results may not be reproducible in patients with advanced stages of the disease. This is particularly relevant as fall frequency is thought to have an inverted U-shaped curve mediated by ambulatory activity that decreases as disease severity increases ${ }^{37}$. Lastly, our model showed an adequate goodness of fit but found that the variance was lower than that reported by other authors ${ }^{38}$. This may be due to the complex multifactorial nature of falling prediction. Other models with higher predictive values included different variables including physical activity ${ }^{39}$, past falling and fear of falling ${ }^{40}$, the retropulsion test and tandem gait ${ }^{41}$. These variables were not individually assessed although the retropulsion test and gait were included in the MDS-UPDRS part III and used to classify PwP within the motor subtypes.

In conclusion, our study identified several motor and non-motor symptoms as factors associated with falls in PwP, but only the disease duration and PIGD remained as independent predictors after multivariate analysis. These findings suggest a more intensive approach in fall prevention among PwP with this subtype. On the other hand, longitudinal studies with PwP in early disease stages are warranted.

\section{References}

1. Allen NE, Schwarzel AK, Canning CG. Recurrent falls in Parkinson's disease: a systematic review. Parkinsons Dis. 2013;2013:906274. https://doi.org/10.1155/2013/906274

2. Thurman DJ, Stevens JA, Rao JK. Practice parameter: assessing patients in a neurology practice for risk of falls (an evidence-based review): report of the Quality Standards Subcommittee of the American Academy of Neurology. Neurology. 2008 Feb;70(6):473-9. https://doi.org/10.1212/01.wnl.0000299085.18976.20

3. Marck MA, Klok MP, Okun MS, Giladi N, Munneke M, Bloem BR. Consensus-based clinical practice recommendations for the examination and management of falls in patients with Parkinson's disease. Parkinsonism Relat Disord. 2014 Apr;20(4):360-9. https://doi.org/10.1016/j.parkreldis.2013.10.030
4. Postuma RB, Berg D, Stern M, Poewe W, Olanow CW, Oertel W, et al. MDS clinical diagnostic criteria for Parkinson's disease. Mov Disord. 2015 Oct;30(12):1591-601. https://doi.org/10.1002/mds.26424

5. Tomlinson CL, Stowe R, Patel S, Rick C, Gray R, Clarke CE. Systematic review of levodopa dose equivalency reporting in Parkinson's disease. Mov Disord. 2010 Nov;25(15):2649-53. https://doi.org/10.1002/mds.23429

6. Hoehn MM, Yahr MD. Parkinsonism: onset, progression, and mortality. 1967. Neurology. 1998 Feb;50(2):318. https://doi.org/10.1212/WNL.50.2.318

7. Martinez-Martin P, Rodriguez-Blazquez C, Alvarez-Sanchez M, Arakaki T, Bergareche-Yarza A, Chade A, et al. Expanded and independent validation of the Movement Disorder Society-Unified 
Parkinson's Disease Rating Scale (MDS-UPDRS). J Neurol. 2013 Jan;260(1):228-36. https://doi.org/10.1007/s00415-012-6624-1

8. Chaudhuri KR, Martinez-Martin P, Brown RG, Sethi K, Stocchi F, Odin $P$, et al. The metric properties of a novel non-motor symptoms scale for Parkinson's disease: results from an international pilot study. Mov Disord. 2007 Oct;22(13):1901-11. https://doi.org/10.1002/mds.21596

9. Stebbins GT, Goetz CG, Burn DJ, Jankovic J, Khoo TK, Tilley BC. How to identify tremor dominant and postural instability/gait difficulty groups with the movement disorder society unified Parkinson's disease rating scale: comparison with the unified Parkinson's disease rating scale. Mov Disord. 2013 May;28(5):668-70. https://doi.org/10.1002/mds.25383

10. Ray Chaudhuri K, Rojo JM, Schapira AH, Brooks DJ, Stocchi F, Odin P, et al. A proposal for a comprehensive grading of Parkinson's disease severity combining motor and non-motor assessments: meeting an unmet need. PLoS One. 2013;8(2):e57221. https://doi.org/10.1371/journal.pone.0057221

11. Chaudhuri KR, Sauerbier A, Rojo JM, Sethi K, Schapira AH, Brown RG, et al. The burden of non-motor symptoms in Parkinson's disease using a self-completed non-motor questionnaire: a simple grading system. Parkinsonism Relat Disord. 2015 Mar;21(3):287-91. https://doi.org/10.1016/j.parkreldis.2014.12.031

12. Pickering RM, Grimbergen YA, Rigney U, Ashburn A, Mazibrada G, Wood B, et al. A meta-analysis of six prospective studies of falling in Parkinson's disease. Mov Disord. 2007 Oct;22(13):1892-900. https://doi.org/10.1002/mds.21598

13. Schrag A, Choudhury M, Kaski D, Gallagher DA. Why do patients with Parkinson's disease fall? A cross-sectional analysis of possible causes of falls. NPJ Parkinsons Dis. 2015 Jun;1(1):15011. https://doi.org/10.1038/npjparkd.2015.11

14. Balash Y, Peretz C, Leibovich G, Herman T, Hausdorff JM, Giladi N. Falls in outpatients with Parkinson's disease: frequency, impact and identifying factors. J Neurol. $2005 \mathrm{Nov}$;252(11):1310-5. https://doi.org/10.1007/s00415-005-0855-3

15. Rudzińska M, Bukowczan S, Stożek J, Zajdel K, Mirek E, Chwała W, et al. The incidence and risk factors of falls in Parkinson disease: prospective study. Neurol Neurochir Pol. 2013 Sep-Oct;47(5):431-7. https://doi.org/10.5114/ninp.2013.38223

16. Lord S, Galna B, Yarnall AJ, Morris R, Coleman S, Burn D, et al. Natural history of falls in an incident cohort of Parkinson's disease: early evolution, risk and protective features. J Neurol. 2017 Nov;264(11):2268-76. https://doi.org/10.1007/s00415-017-8620-y

17. Contreras A, Grandas F. Risk of falls in Parkinson's disease: a crosssectional study of 160 patients. Parkinsons Dis. 2012;2012:362572. https://doi.org/10.1155/2012/362572

18. Hiorth YH, Alves G, Larsen JP, Schulz J, Tysnes OB, Pedersen KF. Long-term risk of falls in an incident Parkinson's disease cohort: the Norwegian ParkWest study. J Neurol. 2017 Feb;264(2):364-72. https://doi.org/10.1007/s00415-016-8365-z

19. Latt MD, Lord SR, Morris JG, Fung VS. Clinical and physiological assessments for elucidating falls risk in Parkinson's disease. Mov Disord. 2009 Jul;24(9):1280-9. https://doi.org/10.1002/mds.22561

20. Keus SH, Bloem BR, Hendriks EJ, Bredero-Cohen AB, Munneke $\mathrm{M}$; Practice Recommendations Development Group. Evidencebased analysis of physical therapy in Parkinson's disease with recommendations for practice and research. Mov Disord. 2007 Mar;22(4):451-60. https://doi.org/10.1002/mds.21244

21. Jankovic J. Parkinson's disease: clinical features and diagnosis. J Neurol Neurosurg Psychiatry. 2008 Apr;79(4):368-76. https://doi.org/10.1136/jnnp.2007.131045

22. Heeden JF, Marinus J, Martinez-Martin P, RodriguezBlazquez C, Geraedts VJ, van Hilten JJ. Postural instability and gait are associated with severity and prognosis of Parkinson disease. Neurology. 2016 Jun;86(24):2243-50. https://doi.org/10.1212/WNL.0000000000002768
23. Arie L, Herman T, Shema-Shiratzky S, Giladi N, Hausdorff JM. Do cognition and other non-motor symptoms decline similarly among patients with Parkinson's disease motor subtypes? Findings from a 5-year prospective study. J Neurol. 2017 Oct;264(10):2149-57. https://doi.org/10.1007/s00415-017-8605-x

24. Simuni T, Caspell-Garcia C, Coffey C, Lasch S, Tanner C, Marek K. How stable are Parkinson's disease subtypes in de novo patients: analysis of the PPMI cohort? Parkinsonism Relat Disord. 2016 Jul;28:62-7. https://doi.org/10.1016/j.parkreldis.2016.04.027

25. Alvarado-Franco NL, Olguín-Ramírez L, Eisinger RS, RamírezZamorra A, Cervantes-Arriaga A, Rodríguez-Valente M, et al. Analysis of Parkinson's disease motor subtypes: Mexican Registry of Parkinson - ReMePARK. Rev Mex Neuroci. 2018;19(5):3-8.

26. Almeida LR, Valenca GT, Negreiros NN, Pinto EB, Oliveira-Filho J. Predictors of recurrent falls in people with Parkinson's disease and proposal for a predictive tool. J Parkinsons Dis. 2017;7(2):313-24. https://doi.org/10.3233/JPD-160934

27. Kim JS, Jang W, Cho JW, Ahn JY, Kim HT. Bedside cognitive assessments and falls risk in Parkinson's disease. Neurol Sci. 2013 Jan;34(1):75-8. https://doi.org/10.1007/s10072-011-0906-8

28. Sixel-Döring F, Trautmann E, Mollenhauer B, Trenkwalder C. Associated factors for REM sleep behavior disorder in Parkinson disease. Neurology. 2011 Sep;77(11):1048-54. https://doi.org/10.1212/WNL.0b013e31822e560e

29. Williams DR, Watt HC, Lees AJ. Predictors of falls and fractures in bradykinetic rigid syndromes: a retrospective study. J Neurol Neurosurg Psychiatry. 2006 Apr;77(4):468-73. https://doi.org/10.1136/jnnp.2005.074070

30. Bryant MS, Rintala DH, Hou JG, Rivas SP, Fernandez AL, Lai EC, et al. The relation of falls to fatigue, depression and daytime sleepiness in Parkinson's disease. Eur Neurol. 2012;67(6):326-30. https://doi.org/10.1159/000335877

31. Parashos SA, Wielinski CL, Giladi N, Gurevich T. Falls in Parkinson disease: analysis of a large cross-sectional cohort. J Parkinsons Dis. 2013;3(4):515-22. https://doi.org/10.3233/JPD-130249

32. Soliman Y, Meyer R, Baum N. Falls in the elderly secondary to urinary symptoms. Rev Urol. 2016;18(1):28-32.

33. Mitchell RJ, Lord SR, Harvey LA, Close JC. Associations between obesity and overweight and fall risk, health status and quality of life in older people. Aust N Z J Public Health. 2014 Feb;38(1):13-8. https://doi.org/10.1111/1753-6405.12152

34. Schrag A, Barone P, Brown RG, Leentjens AF, McDonald WM, Starkstein S, et al. Depression rating scales in Parkinson's disease: critique and recommendations. Mov Disord. 2007 Jun;22(8):1077-92. https://doi.org/10.1002/mds.21333

35. Leentjens AF, Dujardin K, Marsh L, Martinez-Martin P, Richard IH, Starkstein SE, et al. Anxiety rating scales in Parkinson's disease: critique and recommendations. Mov Disord. 2008 Oct;23(14):201525. https://doi.org/10.1002/mds.22233

36. Fernandez HH, Aarsland D, Fénelon G, Friedman JH, Marsh L, Tröster Al, et al. Scales to assess psychosis in Parkinson's disease: critique and recommendations. Mov Disord. 2008 Mar;23(4):484-500. https://doi.org/10.1002/mds.21875

37. Mactier K, Lord S, Godfrey A, Burn D, Rochester L. The relationship between real world ambulatory activity and falls in incident Parkinson's disease: influence of classification scheme. Parkinsonism Relat Disord. 2015 Mar;21(3):236-42. https://doi.org/10.1016/j.parkreldis.2014.12.014

38. Kerr GK, Worringham CJ, Cole MH, Lacherez PF, Wood JM, Silburn PA. Predictors of future falls in Parkinson disease. Neurology. 2010 Jul;75(2):116-24. https://doi.org/10.1212/WNL.0b013e3181e7b688

39. Custodio N, Lira D, Herrera-Perez E, Montesinos R, CastroSuarez S, Cuenca-Alfaro J, et al. Predictive model for falling in Parkinson disease patients. eNeurologicalSci. 2016 Nov;5:20-4. https://doi.org/10.1016/j.ensci.2016.11.003 
40. Wood BH, Bilclough JA, Bowron A, Walker RW. Incidence and prediction of falls in Parkinson's disease: a prospective multidisciplinary study. J Neurol Neurosurg Psychiatry. 2002 Jun;72(6):721-5. https://doi.org/10.1136/jnnp.72.6.721
41. Lindholm B, Nilsson MH, Hansson O, Hagell P. External validation of a 3 -step falls prediction model in mild Parkinson's disease. J Neurol. 2016 Dec;263(12):2462-9. https://doi.org/10.1007/s00415-016-8287-9 